\title{
Applying ISO:31000:2018 as Risk Management Strategy on Heavy Machinery Vehicle Division
}

\author{
Ananto Yusuf Wicaksono \\ Warsaw University of Life Scienceso, Nowoursynowska, Poland
}

\begin{abstract}
A B S T R AC T
The operation of heavy machinery vehicles and extensive project site areas are constrained in a general contractor services business, they need risk management to overcome obstacles that interfere project.. Transporting heavy machinery vehicles from one project location to another project site using low bed movers have a risk. Ideal condition for company heavy machinery vehicle with minimum transport. Despite their completion to represent low budget to manage project, it mitigation time, embarkation and debarkation is a challenge too. The aim of this research is to observe level of effectiveness in applying ISO 31000:2018 risk management standard in heavy machinery operations. We apply expert judgment in risk assessment techniques using questioner. This was distributed to respondents who had experience operating heavy machinery vehicles for at least 3 years. Heavy machinery vehicle operators must have enough experience and maintenance of heavy machinery just conduct routinely based on a manual book. From the results of risk identification, there are 20 risks. Based on the results of the risk assessed from probability and impact variables, damaged risk to the undercarriage parts (R12) as a top priority treatment risk. Risk management will be identified as mitigation strategies based on 5 aspects. They are avoided risk, risk control, separating risk, moving risk and accepting risk. Results of identification from treatment strategies will be assessed based on mitigation duration and mitigation costs, to find out the most optimal strategy for dealing with these risks. It can concluding assessment of risk management strategies well, if mitigation strategies separate risks. is the most optimal mitigation strategy.
\end{abstract}

Keywords: General Contractor, Heavy Machinery Vechile, ISO 31000:2018, Management Risk, Mitigation.

Article History

Received 07 November 2019

Received in revised form 04 February 2020

Accepted 07 May 2020

\section{Introduction}

Risk management interpreting as a systematic way to identify any risks that will occur, analyze and minimize risks to prevent losses to achieve company targets [1][2]. The risk of a company can be bigger and complex, it mean if activities in a company became complexity and uncertainties, the risk will be bigger to be mitigate [3]. Benefits from implementing risk management in a company are to with facilitate cost estimation, make decisions in dealing with problems that will come [4].

Base on observations on a general contractor company, this company has several divisions that are relate to running a business process and play a direct role in supporting the main business. They have five aspect that interrelate to support their main business as a general contractor. They are industrial, environmental, energy, infrastructural and road.

Heavy machinery division is a one important to supporting activities of this company. In actuate of this business process, heavy machinery division cannot separate with risk and based on interviews to field supervisor, there are some possibilities risks might appear in heavy equipment division. This can disrupt business processes in company, they are equipment damage, fuel scarcity, difficulty to find spare parts, and a number of heavy machinery vehicles. based on that risk possibilities that will occur in heavy equipment division can if risks are likely to occur can disrupt the course of the company's business processes and can directly reduce the profit of the company. Therefore, heavy machinery vehicles, risk management is a requirement.

ISO 31000:2018 provides more strategic guidance than ISO 31000:2009 and places more emphasis on both the involvement of senior management and the integration of risk management into the organization [5]. This includes the recommendation to develop a statement or policy that confirms a commitment to risk management, assigning authority, responsibility and accountability at the appropriate levels within the organization and ensuring that the necessary resources are allocated to managing risk [6].

The revised standard now also recommends that risk management be part of the organization's structure, processes, objectives, strategy and activities. It places a greater focus on creating value as the key driver of risk management and features other related principles such as continual improvement, the inclusion of stakeholders, being customized to the organization and consideration of human and cultural factors [7].

\footnotetext{
* Corresponding author. Phone : +48-507-198-201

E-mail address: wicak@interia.pl
} 


\section{Literature Review}

\subsection{Risk Management}

Risk is a necessary part of doing business, and in a world where enormous amounts of data are processed at increasingly rapid rates, identifying and mitigating risks is a challenge for any company. It is no wonder then that many contracts and insurance agreements require solid evidence of good risk management practice [8]. Risk management process applied in research. Then, it determine by expert judgment. That process starting from risk determination, risk assessment, and determination of risk management strategies. Risk management process stage following.

\section{- Risk Identification}

Risk identification is stage to find out risks might appear in a business activity. The process of risk identification in this study conducted by distributing open questionnaires to each chef division company. Risk identification in this research based on business activities by each company division.

- Risk analysis

Risk analysis count from two variables, they are risk predicate probabilities and impact of risk damage. The rating scale flown.

\subsection{Risk Evaluation}

Project management is the practice of initiating, planning, executing, controlling, and closing the work of a team to achieve specific goals and meet specific success criteria at the specified time. The primary challenge of project management is to achieve all of the project goals within the given constraints [9]. Risk evaluation to determine risks that have a significant impact will become a top priority treatment based on the results of risk analysis. In this experiment, risk evaluation is determining quantitatively using two methods, using equation:

- Risk Priority Number (RPN)

Assessment got from the probabilities predicate $(\mathrm{Pp})$ with impact of damage (Id). Flown mathematical equation is:

$$
R P N=P p x I d
$$

- Risk Level Mapping (RLM)

Show the priority of risks, must be mitigate bas on predicate possibility value with impact damage from each risk. Then the next step will be plot into a risk level map. Very High risk marked with red, then will be a top priority in the risk management phase. We can see the risk level map in Figure 1. The label meaning from figure 1; very high risk marked with red it means has a huge damage effect and probability might appear very high. It will be top High risk marked with orange that has a large damage effect and frequently. Require to mitigate. Yellow mark for risk that has a moderate impact and probabilities, monitoring procedures needed and require management responsibilities. Green Risks that have a moderate impact and frequently, need periodic monitoring.

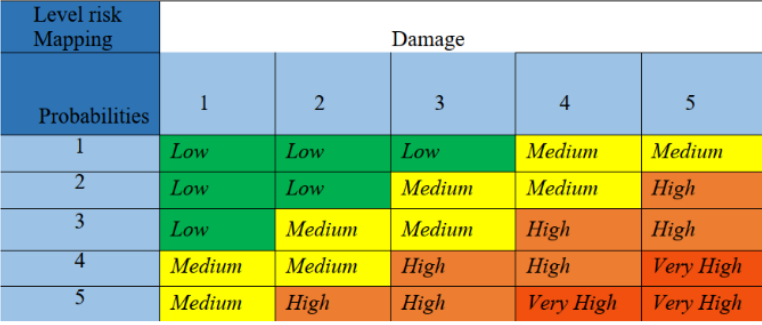

Figure 1. Level risk mapping

\subsection{Risk Mitigation}

Risk mitigation process based on highest impact and probabilities. There are two stages in the risk mitigation process, identifying risk mitigation strategies. Then, identified strategies are evaluated by considering the time and cost needed to realize strategies.

- Identification of Risk Management Strategies

First steps to determine risk management strategy is identifying the handling strategy using a questionnaire identifying the risk management strategy.

- Evaluation of Risk Management Strategies

Evaluation of risk management strategies are used to determine mitigation strategy which will be a proposal for companies to handle risk events, namely by looking at the time of risk handling and the assessment of risk management costs. Table 1 shown scale for assessing risk management strategies.

Table 1. Evaluation of risk management scale.

\begin{tabular}{lcc}
\hline Criteria & Range & Prioritiy level \\
\hline Very low loss & Zł $0-$ Zt 52755,69 & 5 \\
Low loss & Zł 52755,70 - Zł 103515,22 & 4 \\
Moderate loss & Zł 103515,23 - Zł 154559,92 & 3 \\
Big loss & Zł 154559,93 - Zł 205604,61 & 2 \\
Very big loss & Zł 205604,62 - Zł 288017,56 & 1 \\
\hline
\end{tabular}

Table 2. Duration of mitigation scale.

\begin{tabular}{lcc}
\hline Criteria & Range & $\begin{array}{c}\text { Prioritiy } \\
\text { level }\end{array}$ \\
\hline Urgent & Less than 1 work hour & 1 \\
Moderate & More than 1 work hours and less than 8 work hours & 2 \\
Swift & More than 8 work hours and less than 40 work hours & 3 \\
Trivial & More than 40 work hours and less than 120 work hours & 4 \\
Leisure & More than 120 work hours & 5 \\
\hline
\end{tabular}




\subsection{Mitigation Priority Number}

Mitigation Priority Number (MPN) calculated by multiplying the value from duration to mitigate $(\mathrm{Dm})$ with mitigate fee $(\mathrm{Fm})$. Where the mathematical equation is:

$M P N=D m \times F m$

\subsection{Hydraulic bending}

Many tube bending approaches have been developed in response to diverse demands of tube specification, shapes, materials and forming tolerance. There are cold bending at room temperature and heat bending with elevated temperature. In some perspective that caused loading conditions, there are pure bending, compression bending, stretch bending, roll bending, rotary draw bending and laser bending [10]. Observed heavy machinery vehicle has hydraulic damage, so can interperent project's process.

\section{Methods}

This research conducting on Mostostal Warszawa SA, it is one of the largest construction companies in Poland. Company has been operating in Poland over seven decades and implementation of all types of construction facilities: general, industrial, environmental, energy, infrastructural and road. Within variable :

\section{- $\quad$ Risk}

Risk is an event that might be appear in business activities that can. It can disrupt project process, will be main focus on this research

- $\quad$ Predicate of probabilities

Predicate of possibility might be appear risk. some say level of frequency risk recognoizing.

- Impact of Losses

Is a material loss consequence that must be covered by company if the risk appear in business activity.

- Mitigation duration

It is an estimate of how long it will take to realize the risk mitigation strategy.

- Mitigation handling

It is an estimate of how much it will cost to realize the risk mitigation strategy.

In this research, respondents determine based on purposive sampling technique in which the purposive sampling technique was a way of taking samples under the required sample requirements such as characteristics, characteristics, criteria. Based on the purposive sampling technique, the sample or respondents are technical / operation manager, head of the heavy equipment division, head of the engineering team, and the head of the welding team who are the people who know the real condition of the business process of the heavy equipment division and have work experience in three years. This research flown sung flowchart shown on image 2 .

\section{Result}

\subsection{Risk identification}

In this research, risk identification conducted by distributing open questionnaires to some respondents they are technical / operation manager, section manager, engineering supervisor, and welding supervisor. Risk identification based on heavy machinery vehicle division business activities. Table 3 shown risk identification scale.

Table 3. Evaluation of risk management scale.

\begin{tabular}{|c|c|c|c|c|}
\hline Risk & $\begin{array}{l}\text { Risk } \\
\text { Code }\end{array}$ & Probalities & Damaged & RPN \\
\hline $\begin{array}{c}\text { Hydraulic pipe being damaged } \\
\text { when digging }\end{array}$ & R 1 & 3 & 2 & 6 \\
\hline $\begin{array}{l}\text { The running of bulldozer has } \\
\text { anomaly }\end{array}$ & R 2 & 4 & 2 & 8 \\
\hline $\begin{array}{l}\text { Track roller has damaged on } \\
\text { track shoe }\end{array}$ & R 3 & 4 & 2 & 8 \\
\hline $\begin{array}{l}\text { Heavy machinery vehicle } \\
\text { component has fatigue }\end{array}$ & R 4 & 2 & 1 & 2 \\
\hline $\begin{array}{l}\text { Heavy machinery vehicle not } \\
\text { ready }\end{array}$ & R 5 & 3 & 2 & 6 \\
\hline Demonstrasion & R 6 & 1 & 5 & 5 \\
\hline Spare part loss & R 7 & 4 & 1 & 4 \\
\hline Miss-configuration & R 8 & 2 & 1 & 2 \\
\hline Spare part not ready & R 9 & 3 & 2 & 6 \\
\hline Lubrication engine fatigue & R 10 & 3 & 3 & 9 \\
\hline Damage on engine spare part & R 11 & 3 & 2 & 6 \\
\hline $\begin{array}{c}\text { Damage on undercarriage } \\
\text { parts }\end{array}$ & R 12 & 4 & 5 & 20 \\
\hline $\begin{array}{l}\text { Damage on bucket wheel } \\
\text { excavator }\end{array}$ & R 13 & 4 & 2 & 8 \\
\hline $\begin{array}{c}\text { bucket wheel excavator } \\
\text { hydraulic damaged }\end{array}$ & R 14 & 4 & 2 & 8 \\
\hline $\begin{array}{c}\text { Bucket wheel excavator life } \\
\text { time }\end{array}$ & R 15 & 4 & 1 & 4 \\
\hline Trouble on joining thick plat & R 16 & 3 & 2 & 6 \\
\hline Loss on gear joining & R 17 & 4 & 1 & 4 \\
\hline Bucket plat loss & R 18 & 4 & 1 & 4 \\
\hline Bad weld joining & R 19 & 4 & 1 & 4 \\
\hline Welding not ready & R 20 & 3 & 1 & 3 \\
\hline
\end{tabular}

\subsection{Risk analysist}

The aim of risk analysis is to get an assessment of risks that have been identified. In this research, risk assess based on two variables, probability predicate and impact of risk. From table 3 we can see risk analysis based on probabilities and damaged. 


\subsection{Risk evaluation}

Risk evaluation is conducted to determine risks thats might appear and become priorities that must be mitigate. To determine this, use the Risk Priority Number (RPN) tool and a risk level map.

From the calculation of RPN on table 3, the top priorities is risk of damage undercarriage parts (R12). The value is 20 and it dominate than others. Based on the respondent's information the possibility of damage to the undercarriage parts is very large because undercarriage component is important to support heavy machinery vehicle operation and it be a chassis. From the results of risk map we can see it be top priority to mitigate.

\subsection{Risk mitigation}

Risk mitigation conducting on risks that have most frequently to appear with big impact of losses, it can see from table 4 . The focus of mitigation are risk of damage on undercarriage parts (R12).

Table 4. Risk mitigation strategies.

\begin{tabular}{|c|c|c|}
\hline $\begin{array}{l}\text { Strategies } \\
\text { code }\end{array}$ & $\begin{array}{c}\text { Type of } \\
\text { mitigation }\end{array}$ & Mitigate strategies \\
\hline S1 & Avoid the risk & $\begin{array}{l}\text { field observation before choosing a } \\
\text { type heavy machinery vehicle. for } \\
\text { heavy terrain, use rigid-tracked heavy } \\
\text { machinery vehicle. If moderate or } \\
\text { lower terrain we can use semi rigid- } \\
\text { tracked. For urban area using wheeled } \\
\text { one }\end{array}$ \\
\hline S2 & Control the risk & $\begin{array}{l}\text { Operators who operate heavy } \\
\text { machinery vehicle must have } \\
\text { enough experience and heavy } \\
\text { machinery vehicle has maintenance } \\
\text { must be conducting base on standard } \\
\text { procedure }\end{array}$ \\
\hline S3 & Separate the risk & if the tracked one is not ready, rent it \\
\hline S4 & Moving the risk & Insurance every operational vehicle \\
\hline S5 & Accepting the risk & $\begin{array}{c}\text { Ready to repair if has any damage on } \\
\text { under carriage part }\end{array}$ \\
\hline
\end{tabular}

From risk mitigation strategy on table 4 it noticed that avoid risk (field observation before choosing a type heavy machinery vehicle. for heavy terrain, use rigid-tracked heavy machinery vehicle. If moderate or lower terrain we can use semi rigid-tracked. For urban area using wheeled one) gets a time assessment score of 1 and a cost of 5 so that this handling strategy gets the highest RPN value, then it is not a priority proposed handling strategies.

Control risk (Operators who operate heavy machinery vehicle must have enough experience and heavy machinery vehicle has maintenance must be conducting base on standard procedure) is the most optimal proposed handling strategy, we can see it from the evaluation of the time to get an assessment score of 2 and for the cost assessment of getting an assessment score 1 so results of multiplication both assessment variables get smallest RPN value.

\section{Conclusion}

Results of identification of risks carried out through 4 respondents who have an important role in the division of Mostostal Warszawa SA heavy equipment obtained 20 risks that can disrupt the course of their heavy machinery division process. Based on risk evaluation stage using Risk Priority Number (RPN) tool and risk level map, it can be see if risk of damage to undercarriage parts (R12) as a risk will be a priority for risk management. We seen from assessment of risk management strategies if mitigate strategy separates risks (heavy equipment operators must be experienced and heavy maintenance routine follow their manual book) is the most optimal proposed handling strategy.

\section{REFERENCES}

[1] M. Munir, M. S. Sadiq Jajja, K. A. Chatha, and S. Farooq, 'Supply Chain Risk Management and Operational Performance: The Enabling Role of Supply Chain Integration', Int. J. Prod. Econ., p. 107667, 2020, doi: https://doi.org/10.1016/j.ijpe.2020.107667.

[2] M. A. Ekemen and S. Harun, 'Data in brief Dataset on social capital and knowledge integration in project management', no. February, pp. 1-6, 2020, doi: 10.1016/j.dib.2020.105233.

[3] J. Young, 'Risk management', Aviat. Week Sp. Technol. (New York), vol. 165, no. 5, pp. 44-45, 2018.

[4] Y. Ozturkoglu, Y. Kazancoglu, and Y. D. Ozkan-Ozen, 'A sustainable and preventative risk management model for ship recycling industry', J. Clean. Prod., vol. 238, p. 117907, 2019, doi: https://doi.org/10.1016/j.jclepro.2019.117907.

[5] Y. Jung, S. Kang, Y.-S. Kim, and C. Park, 'Assessment of safety management information systems for general contractors', Saf. Sci., vol. 46, no. 4, pp. 661-674, 2008, doi: https://doi.org/10.1016/j.ssci.2007.06.009.

[6] R. Picciotto, 'Towards a "New Project Management" movement? An international development perspective', Int. J. Proj. Manag., 2019, doi: https://doi.org/10.1016/j.ijproman.2019.08.002.

[7] R. F. de Toledo, H. L. Miranda Junior, J. R. Farias Filho, and H. G. Costa, 'A scientometric review of global research on sustainability and project management dataset', Data Br., vol. 25, p. 104312, 2019, doi: 10.1016/j.dib.2019.104312.

[8] C. M. Meyer and E. L. G. Torres, 'Success Factors for Supply Chain Management Projects: An Empirical Analysis', IFACPapersOnLine, vol. 52, no. 13, pp. 153-158, 2019, doi: 10.1016/j.ifacol.2019.11.168.

[9] B. Koke and R. C. Moehler, 'Earned Green Value management for project management: A systematic review', J. Clean. Prod., vol. 230, pp. 180-197, 2019, doi: 
https://doi.org/10.1016/j.jclepro.2019.05.079.

[10] H. Yang, H. Li, Z. Zhang, M. Zhan, J. Liu, and G. Li,

'Advances and trends on tube bending forming technologies',

Chinese J. Aeronaut., vol. 25, no. 1, pp. 1-12, 2012, doi:

10.1016/S1000-9361(11)60356-7. 